\title{
Sex-Specific Foraging Behaviours and Growth Rates in Juveniles Contribute to the Development of Extreme Sexual Size Dimorphism in a Spider
}

\author{
S. Andrew Inkpen ${ }^{1, \dagger}$ and Matthias W. Foellmer ${ }^{*}, 2$ \\ ${ }^{I}$ Department of Biology, Saint Mary's University, 923 Robie Street, Halifax, NS, B3H 3C3, Canada \\ ${ }^{2}$ Department of Biology, Adelphi University, 1 South Ave., Garden City, NY, 11530, USA
}

\begin{abstract}
Extreme sexual size dimorphism (SSD) in temperate species is expected to be proximally caused, at least partially, by sex-specific growth rates due to the limited time available for growth and reproduction. Hence sex-specific foraging strategies are predicted to mediate differential growth rates. However, little is known about how sex differences in foraging behaviour and growth trajectories relate to the expression of pronounced SSD. Here we tested for sex-specific foraging strategies and growth rates in juveniles of the highly size dimorphic orb-web spider Argiope aurantia under natural conditions. In a number of web sites, we estimated web height, web size (size of the prey capture area), mesh size, stabilimentum (web decoration) size and length, vegetation density and prey availability. Over four days in the field we also measured spider growth and web site tenacity. Independently of body size, females exhibited faster growth rate than males. When body size and condition were controlled for, we found that females built larger webs, and at sites with greater prey availability compared to males. Males built webs with significantly larger and longer stabilimenta independent of web size. These results indicate that extreme female-biased SSD in A. aurantia is at least partially the result of sex-specific growth rates already in early juvenile stages mediated by sex-specific web design and placement to allow for greater foraging success of females compared to males. We discuss these findings in the context of SSD evolution, and consider whether the sex-specific behaviours detected are more likely consequences or causes of the evolution of extreme SSD.
\end{abstract}

Keywords: Behavioural evolution, black-and-yellow garden spider, orb-web design, sexual dimorphism, trade-off.

\section{INTRODUCTION}

According to the differential equilibrium model for sexual size dimorphism (SSD), SSD is ultimately the result of opposing selection forces equilibrating differently in the sexes (Blanckenhorn 2005, Fairbairn et al. 2007). The outcome is a common but variable pattern throughout the animal kingdom in which the mean body size of adult males and females differs. In species of birds and mammals, males are usually the larger sex, whereas in ectotherms females are typically larger (Fairbairn 1997). Spiders exhibit the entire range of SSD from female-biased to male-biased (Head 1995, Vollrath 1998, Foellmer and Moya-Laraño 2007) and are the only free-living terrestrial taxon where extreme female-biased SSD is common (Ghiselin 1974, Vollrath 1998). In those genera of orb-weaving spiders (Orbiculariae) and crab spiders (Thomisidae), where extreme female-biased SSD occurs prevalently, females may weigh more than one hundred times as much as males (Head 1995, Vollrath 1998), and extreme SSD has evolved several times independently (Hormiga et al. 2000). For these reasons spiders have

*Address correspondence to this author at the Department of Biology, Adelphi University, 1 South Ave., Garden City, NY, 11530, USA; Tel: +1516-877-4206; Fax: +1-516-877-4209; E-mail: Foellmer@adelphi.edu

${ }^{\dagger}$ Current address: Department of Philosophy, University of British Columbia, 1866 Main Mall E370, Vancouver, BC, V6T 1Z1, Canada

Special Issue Editor: Valenti Rull become a model group to study SSD evolution (Foellmer and Moya-Laraño 2007).

To date, most studies investigating the significance of SSD have focused on macroevolutionary patterns and micrevolutionary processes of SSD evolution (Fairbairn et al. 2007), although notable progress has been made recently in understanding the genetic and developmental underpinnings (i.e., proximate causes) of SSD in animals (e.g. Blanckenhorn et al. 2007, reviewed in Fairbairn et al. 2007). However, for insects and spiders, for example, it is still controversial to what extent sex-specific growth rate, development time, or both, mediate the ontogeny of SSD (Blanckenhorn et al. 2007, Blanckenhorn 2005, Esperk et al. 2007), and little is known about the behavioural differences between males and females that accompany sex-specific growth and development (Blanckenhorn 2005, Mikolajewski et al. 2007).

Both growing faster and growing longer to achieve large adult size are strategies that have implications. For example, faster growing individuals should pursue a foraging strategy that assures high foraging success and reduces foraging risk (i.e., variance in foraging success) (Uetz 1992, Werner and Anholt 1993). However, increased foraging effort can be expected to come with the cost of an increased mortality risk due to increased exposure to predators or potentially dangerous prey (Werner and Anholt 1993, Mikolajewski et al. 2007). Longer growth duration causes a prolonged juvenile 
stage with an accompanying larger cumulative mortality risk and a shortened mating season (Blanckenhorn 2005, Higgins 2000). In highly dimorphic spider species, current evidence suggests that large females grow both faster and for a longer time than males (Blanckenhorn et al. 2007, Esperk et al. 2007), but nothing is known about the nature of sex-specific foraging strategies in juveniles and how males and females trade-off foraging risk and mortality risk differently during their ontogeny (Foellmer and Moya-Laraño 2007).

Here we examine crucial aspects of the foraging behaviour of young juveniles of the highly dimorphic orbweb spider Argiope aurantia to test the hypothesis that juvenile females pursue a more voracious foraging strategy than juvenile males allowing them to grow at a faster rate and hence to become much larger than males. In particular, in two field studies we test for sex differences in orb-web design and placement, the frequency of web site change, and prey availability at web sites. In addition, we test for sexspecific growth rates in the field during our experimental trial period.

With regards to orb-web design and placement we predicted that females build webs that, relative to males, a) are higher up in less dense vegetation to intercept larger flying prey (e.g. flies $v s$. immature leaf hoppers), b) are placed in spots with more potential prey available, c) have a larger prey capture area, and/or d) have a larger stabilimentum (a conspicuous white silken structure, or web decoration, built in the center of the web). While the first three predictions are obvious (building large webs at sites with high prey availability at a height that allows interception of large prey should enable a spider to obtain a high caloric gain to achieve fast growth), the last one was based on current evidence for stabilimentum function in juvenile conspecific Argiope versicolor. In this species a prey attraction function of the discoid stabilimenta of juveniles was found to be most probable (Li et al. 2004). We further predicted that females change web sites more frequently than males, which would indicate a higher low-food threshold to decrease the variance in foraging success (Uetz 1992, but see Edwards et al. 2009). Finally, we predicted that females grow faster, i.e. gain weight faster than males during our study period.

\section{METHODS}

\section{Study Species}

The orb-web spider $A$. aurantia occurs in successional habitats (e.g. old fields) and is common in eastern North America (Levi 1968). This species exhibits pronounced sexual size dimorphism and females achieve their larger size through both a longer development time and a higher growth rate (Blanckenhorn et al. 2007, Foellmer, Inkpen \& Bowden, unpublished manuscript). Laboratory estimates (all individuals of a given instar fed the same amount and type of food) of adult size (cephalothorax width or $\mathrm{CW}$, which changes only during a spider's moult, and thus not after reaching maturity), development time (days to maturity after moulting to the third instar; spiderlings emerge from the egg sac and overwinter in the second instar, the duration of which is hence not known), and growth rates -computed for a range of instars that both sexes undergo as $[\mathrm{CW}$ instar $6-\mathrm{CW}$ instar
3] / development time between instars 3 and 6- are as follows (means $\pm \mathrm{SE}$; females: $\mathrm{n}=55$; males: $\mathrm{n}=31$, Foellmer, Inkpen \& Bowden, unpublished manuscript): CW - females $=3.7 \pm 0.08 \mathrm{~mm}$, males $=1.9 \pm 0.03 \mathrm{~mm}(\mathrm{t}=$ 22.2 , df $=77.3$, equal variances not assumed, $\mathrm{p}<0.001)$; development time - females $=58.7 \pm 1.11$ days, males $=44.9$ \pm 1.10 days $(\mathrm{t}=-7.7, \mathrm{df}=84, \mathrm{p}<0.001)$; growth rate females $=0.035 \pm 0.001 \mathrm{~mm} / \mathrm{d}$, males $=0.027 \pm 0.001 \mathrm{~mm} / \mathrm{d}$ $(\mathrm{t}=-4.165, \mathrm{df}=84, \mathrm{p}<0.001)$.

\section{Study Site}

This study was carried out in a large old field along highway 101 just outside Wolfville, Nova Scotia, Canada between June 12 and July 11, 2006. The site is characterized by invading shrubs, tall grasses and clovers (Phleum pretense, Agropyron repens, Bromus sp., Chrysanthemum leucanthemum, Trifolium repens, Lotus corniculata, Centaurea nigra, Conyza Canadensis, Tussilago farfara, Solidago sp.). Juveniles were probably in the third and fourth instars, as judged by comparison with laboratory-reared individuals of known age. Note that all spiderlings emerge from an egg sac together and that all egg sacs examined so far contain both males and females (pers. obs.). Therefore, it is highly unlikely that females could get a "jump start" in the field. Their sex was unknown during the field measurements, because at this age males and females have the same color pattern and appear to be of the same size and body shape to the naked eye. No spider exhibited a thickened pedipalp yet, which would be indicative of a juvenile male (Foelix 1996, Mahmoudi et al. 2008). Individuals were brought to the lab after the experimental observations to be reared for later sex identification. Webs were built in grasses (Phleum pretense, Agropyron repens, Bromus $s p$ ) and clover plants (Trifolium repens). As is typical for many orb-web spiders (Foelix 1996), A. aurantia rebuild a new web each day (pers. obs.).

\section{Web Design and Placement}

\section{Data Collection in the Field}

To test for sex differences in web design and web placement, the vegetation within an approximately $30 \mathrm{~m}^{2}$ area was searched with water sprayers to increase the visibility of web structures. When a juvenile $A$. aurantia web was discovered, the spider was collected, the height of the web was measured, pictures were taken of the web and the surrounding vegetation using a Nikon CoolPix 4500 camera, and (for a subset of spiders) a transparent sticky trap was erected for six hours to estimate prey availability. We measured web height as the distance from the ground to the center of the web. The web was dusted with flour to further increase the visibility of web structures when pictures were taken. Each picture contained a measurement bar, laid onto the web, so that the web structures could be later measured with the aid of the image analysis software SigmaScan Pro 5. The vegetation coverage surrounding each web was estimated using a vegetation density estimator that consisted of two bamboo sticks and brightly coloured orange string. The string was tied between the two bamboo sticks, which were $30 \mathrm{~cm}$ apart, every $5 \mathrm{~cm}$ from the ground up to a total of 35 $\mathrm{cm}$. We held the vegetation density estimator straight up 30 $\mathrm{cm}$ behind the web and took a frontal digital picture $30 \mathrm{~cm}$ from the web. This ensured that the entire area's vegetation 


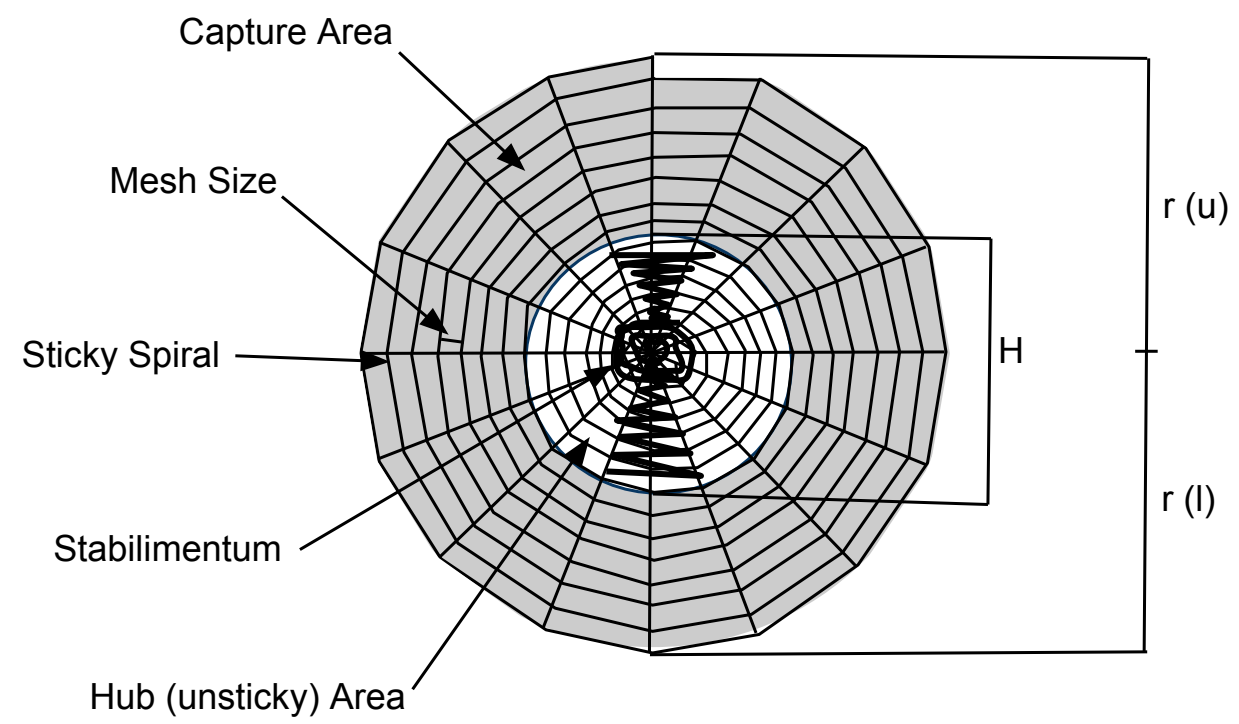

Fig. (1). Schematic representation of a web to illustrate measurements taken in the experiment.

cover next to and around the web could be measured as percent vegetation cover estimated for each string, for which the same software as above was used.

We erected sticky traps at the same location and height as the spider's web for a subset of 39 individuals. They were made of bamboo sticks and $10 \mathrm{~cm} \times 10 \mathrm{~cm}$ transparent acrylic sheets to which Tanglefoot Bird Repellent (a sticky sap that does not dry) was applied. These traps caught any insect which happened to fly or jump into them. We left them erected for a six hour period. We removed all individuals from the traps with forceps and immersed them in ethanolfilled vials. The sticky traps were reused each day after a new coating of Tanglefoot Bird Repellent was applied. The body length of each captured insect and spider caught was measured using a Zeiss Stemi 2000 stereo microscope with an ocular micrometer, and each individual was identified to Order level (total number of individuals $=910$ ).

Upon collection, two pictures were taken of each spider from the dorsal perspective, as the spider was gently held between two lids of Petri dishes balanced with cotton and marked with scale bars. We measured morphological traits from these pictures later on the computer. At the end of each day, spiders collected were brought back to the lab and transferred to small plastic cages. These spiders were raised until their sex could be determined (males: $n=61$; females: $\mathrm{n}=70)$.

\section{Web Measurements}

We measured the following web structures: the upper and lower radii, the hub diameter and area, the stabilimentum length and area, and counted the sticky spirals (Fig. 1). The hub is the center of the web not used for prey capture (i.e., contains no sticky spiral). For $A$. aurantia, the stabilimentum can generally be described as linear (constructed in a vertical line, or close to vertical), or discoid (constructed in a circular spiral shape), or a mix of both. The sticky spiral and the radius can be used to estimate the total capture area, mesh size, and capture thread length according to published formulae. Mesh size and capture thread length are important to understand the structure of the capture area and the nature of potential sex differences ( $\mathrm{Li}$ and Lee 2004, Sandoval 1994). For example, a larger capture area might be accomplished by increasing mesh size, without investing much in longer total thread length, but with the cost of not intercepting many small prey. In particular, we measured stabilimentum length, stabilimentum area, stabilimentum shape (discoid or linear), upper and lower radial length $\left(\mathrm{r}_{u}\right.$ and $\mathrm{r}_{l}$, the distance from the center of the hub to the outermost sticky spiral), hub length $(\mathrm{H}$, vertical diameter of the hub), count of sticky spirals to the left and to the right of the hub ( $\mathrm{ss}_{l}$ and $\mathrm{ss}_{r}$, the number of sticky spiral turns, only in capture area, from the end of the unsticky area to the outermost sticky spiral) and the hub area. Using these measurements we estimated capture area (ellipse - hub formula, Herberstein and Tso 2000), mesh size (Herberstein and Tso 2000) and total capture thread length ( $\mathrm{Li}$ and Lee 2004; Heiling et al. 1998) using the following formulae:

$$
\begin{aligned}
& \text { Capture Area }=\left[\frac{1}{2} \pi r_{u}^{2}-\frac{1}{2} \pi\left(\frac{H}{2}\right)^{2}\right]+\left[\frac{1}{2} \pi r_{l}^{2}-\frac{1}{2} \pi\left(\frac{H}{2}\right)^{2}\right] \\
& \text { Average Mesh Size }=\frac{1}{2}\left[\frac{\left(r_{u}-\frac{H}{2}\right)}{s s_{l}}+\frac{\left(r_{l}-\frac{H}{2}\right)}{s s_{r}}\right]
\end{aligned}
$$

Total Capture Thread Length $=$

$$
\frac{\pi}{2}\left[n_{1}\left(r_{1}+r_{2}\right)+n_{2}\left(r_{2}+r_{3}\right)+n_{3}\left(r_{4}+r_{5}\right)+n_{4}\left(r_{5}+r_{6}\right)\right]
$$

where: $n_{1}, n_{2}=\frac{s s_{l}}{2} ; n_{3}, n_{4}=\frac{s s_{r}}{2} ; r_{1}=\frac{H}{2}$;

$$
\begin{array}{ll}
r_{2}=\frac{1}{2}\left(r_{u}-\frac{H}{2}\right)+\frac{H}{2} ; \quad r_{3}=r_{l} ; & r_{4}=\frac{H}{2} ; \\
r_{5}=\frac{1}{2}\left(r_{l}-\frac{H}{2}\right)+\frac{H}{2} ; r_{6}=r_{l} &
\end{array}
$$




\section{Morphological Measurements}

Each spider's maximum abdomen length and width, as well as maximum cephalothorax width was measured from the photographs. In each case both pictures were measured and the average of both was recorded (all repeatabilities $>$ 0.91). Abdomen area was estimated as the ellipse defined by abdomen length and width. Cephalothorax width is a "fixed" trait that does not change within a given instar. Abdomen area is not fixed and can vary dramatically depending on a spider's condition (i.e., nutritional status) (Foellmer and Moya-Laraño 2007). Hence, cephalothorax width and abdomen area were used in data analysis to control for size and energy reserves (condition) of each spider, respectively, ensuring that only sex differences were tested.

\section{Web Site Change and Growth Rate}

\section{Data Collection in the Field}

Because the previously reported average web site tenacity for juveniles was less than four days (Enders 1976), in order to test for sex-specific web site changes and growth rates we implemented a mark-recapture study during two periods, each lasting four days. On the first day of each set, spiders were located by searching the vegetation thoroughly with water sprayers. When a spider was found, it was collected with a vial without damaging the web. We numbered and marked each web site with florescent tape. Digital pictures of each spider were taken from above and each spider was marked individually using non-toxic acrylic paint. We then returned each spider to its original web where it would settle again promptly. The web sites were checked three and six hours after the spider was returned. Spiders were left in the field for another three days (total observational period $=$ four days) and on days two, three and four of the study we returned to the field in the morning and recorded presence of the spider at approximately $10 \mathrm{am}, 1 \mathrm{pm}$, and $4 \mathrm{pm}$. When a spider was missing from its last recorded site, approximately a 10 meter circular diameter around the web was searched with water sprayers. If the missing spider was found, the distance it had traveled was recorded, and its new web location was marked. If the spider was not found by the end of the experiment it was assumed to have either moulted (removing the marking) and moved, or been killed. When a spider without a marking was found in a web which was marked, we searched the vegetation within a 10 meter diameter area. If the spider was found, the distance it had traveled was recorded. If the spider was not found it was assumed that the spider had moulted, upon which time it was collected and repainted with its corresponding number. If an unmarked spider was found in a marked web along with a moulted skin that was marked, it was assumed to be the same spider and was collected, repainted then returned to its web. Twenty spiders were found after moulting of which 10 lived to maturity ( 5 females, 5 males).

In order to test whether painting or handling have an affect on the spiders we did not handle or paint a number of control spiders $(n=10)$. For these control spiders we only marked the web site with fluorescent tape. We compared these spiders against the marked (experimental) spiders.

At the end of the fourth day all spiders were collected and pictures were taken in the same fashion as on the first day, so that before and after pictures existed for each spider. We used these to also confirm our conclusions about moulting events by comparing the prosoma before and after the assumed moult (during which the prosoma would increase in size). Spiders were brought back to the lab and reared to a sex determinable stage (see above). A total of 138 spiders were initially marked of which 70 (28 males and 42 females) were found at the end of the experiment.

\section{Data Analysis}

Where appropriate, we used either General Linear Models (GLM) or Generalized Linear Models (GLZ) to model the dependent variables as a function of sex (fixed effect) and cephalothorax width and abdomen area to control for size and condition, respectively (covariates). As with multiple regression, in our models the effect of, for example, abdomen area is evaluated independent of cephalothorax width and sex (using a condition variable based on residuals is hence superfluous). For sets of related dependent variables we first ran a multivariate model and if this was significant proceeded with univariate analyses. In all tests involving GLMs or GLZs, we first tested for interaction effects between independent variables. When interactions were not significant, we simplified the models by removing the interaction terms to test for the main affects (Kleinbaum et al. 1998). We included "trial" as a fixed factor in tests based on data from study two to account for the two separate sampling periods. A fixed factor is appropriate here as this reflects our pre-determined experimental sampling scheme and not a random sample of study periods. In all analyses involving sticky traps we used trap means to avoid pseudoreplication.

When necessary, variables were log or Box-Cox transformed to allow for parametric testing. Abdomen area, capture area, stabilimentum area and hub area were first square-root transformed to bring them to a linear scale. Not all measurements could be taken reliably for each spider, hence samples sizes vary. We performed statistical tests with either MINITAB 15 or SPSS 15.

\section{RESULTS}

In both studies (web design and web site change/growth rates) males and females differed in initial size and/or condition. In the web design study, females $(n=70)$ were larger than males $(n=61$; mean cephalothorax width \pm SD: $1.42 \pm 0.36 \mathrm{~mm}$ vs. $1.18 \pm 0.22, \mathrm{t}=4.18, \mathrm{p}<0.001)$, but did not differ from males in condition (sex effect in a GLM with cephalothorax width as a covariate, and abdomen area as dependent variable: $\mathrm{F}_{1,126}=0.460, \mathrm{p}>0.4$ ). In the study examining web site changes and growth rates, of the initial 138 spiders that were included, 70 were present at the end of the experimental observation, and could be reared until the sex could be determined (females: $n=42$; males: $n=28$ ). Females were initially larger than males mean cephalothorax width $\pm \mathrm{SE}$ : females $=1.40 \pm 0.051 \mathrm{~mm}$; males $=1.14 \pm$ $0.055, \mathrm{t}=4.00, \mathrm{p}<0.0001)$, and were also significantly better in condition (sex effect in a GLM with cephalothorax width as a covariate, and abdomen area as dependent variable: $F_{1,67}=5.847, p<0.025$; adjusted means $\pm 95 \% \mathrm{CI}$ : females $=0.283 \pm 0.020$, males $=0.237 \pm 0.017$ ). 
Table 1. Results of GLMs with Size (Cephalothorax Width) and Energy Reserves (Abdomen Area) as Covariates, Sex as the Independent Factor and Web Parameters as Dependent Variables (HA = Hub Area; MS = Mesh Size; TCTL = Total Capture Thread Length; STABA = Stabilimentum Area; STABL = Stabilimentum Length; VEGD = Vegetation Density; WH $=$ Web Height). $b=$ the Slope from the GLM for Continuous Predictors

\begin{tabular}{|c|c|c|c|c|c|c|c|c|}
\hline Dep. Variable & Source & Type III SS & $d f$ & Mean Square & $\boldsymbol{F}$ & $p$ & $\boldsymbol{b}$ & $S E$ \\
\hline \multirow{8}{*}{$\mathrm{HA}$} & Corrected Model & 1.22 & 3 & 0.41 & 64.22 & $<0.0001$ & & \\
\hline & Intercept & 1.61 & 1 & 1.61 & 253.50 & $<0.0001$ & & \\
\hline & Cephalothorax width & 0.47 & 1 & 0.47 & 73.66 & $<0.0001$ & 0.44 & 0.05 \\
\hline & Abdomen area & 0.00 & 1 & 0.00 & 0.00 & $>0.9$ & 0.00 & 0.06 \\
\hline & Sex & 0.01 & 1 & 0.01 & 1.49 & $>0.2$ & & \\
\hline & Error & 0.74 & 117 & 0.01 & & & & \\
\hline & Total & 241.54 & 121 & & & & & \\
\hline & Corrected Total & 1.96 & 120 & & & & & \\
\hline \multirow{8}{*}{ MS } & Corrected Model & 0.21 & 3 & 0.07 & 4.63 & $<0.005$ & & \\
\hline & Intercept & 0.01 & 1 & 0.01 & 0.43 & $>0.5$ & & \\
\hline & Cephalothorax width & 0.02 & 1 & 0.02 & 1.15 & $>0.2$ & 0.08 & 0.08 \\
\hline & Abdomen area & 0.02 & 1 & 0.02 & 1.58 & $>0.2$ & 0.12 & 0.10 \\
\hline & Sex & 0.00 & 1 & 0.00 & 0.07 & $>0.7$ & & \\
\hline & Error & 1.75 & 117 & 0.01 & & & & \\
\hline & Total & 11.21 & 121 & & & & & \\
\hline & Corrected Total & 1.96 & 120 & & & & & \\
\hline \multirow{8}{*}{ TCTL } & Corrected Model & 2.83 & 3 & 0.94 & 24.13 & $<0.0001$ & & \\
\hline & Intercept & 12.74 & 1 & 12.74 & 326.21 & $<0.0001$ & & \\
\hline & Cephalothorax width & 1.39 & 1 & 1.39 & 35.60 & $<0.0001$ & 0.76 & 0.13 \\
\hline & Abdomen area & 0.15 & 1 & 0.15 & 3.96 & $<0.05$ & -0.31 & 0.16 \\
\hline & Sex & 0.18 & 1 & 0.18 & 4.61 & $<0.05$ & & \\
\hline & Error & 4.57 & 117 & 0.04 & & & & \\
\hline & Total & 1395.07 & 121 & & & & & \\
\hline & Corrected Total & 7.40 & 120 & & & & & \\
\hline \multirow{8}{*}{ STABA } & Corrected Model & 1.17 & 3 & 0.39 & 30.04 & $<0.0001$ & & \\
\hline & Intercept & 0.22 & 1 & 0.22 & 17.13 & $<0.0001$ & & \\
\hline & Cephalothorax width & 0.16 & 1 & 0.16 & 12.55 & $<0.001$ & 0.26 & 0.07 \\
\hline & Abdomen area & 0.11 & 1 & 0.11 & 8.53 & $<0.005$ & 0.26 & 0.09 \\
\hline & Sex & 0.10 & 1 & 0.10 & 7.80 & $<0.01$ & & \\
\hline & Error & 1.52 & 117 & 0.01 & & & & \\
\hline & Total & 104.90 & 121 & & & & & \\
\hline & Corrected Total & 2.68 & 120 & & & & & \\
\hline \multirow{8}{*}{ STABL } & Corrected Model & 3.20 & 3 & 1.07 & 67.77 & $<0.0001$ & & \\
\hline & Intercept & 0.90 & 1 & 0.90 & 57.52 & $<0.0001$ & & \\
\hline & Cephalothorax width & 0.88 & 1 & 0.88 & 55.74 & $<0.0001$ & 0.60 & 0.08 \\
\hline & Abdomen area & 0.05 & 1 & 0.05 & 3.38 & $<0.07$ & 0.18 & 0.10 \\
\hline & Sex & 0.06 & 1 & 0.06 & 3.89 & $<0.06$ & & \\
\hline & Error & 1.84 & 117 & 0.02 & & & & \\
\hline & Total & 234.93 & 121 & & & & & \\
\hline & Corrected Total & 5.04 & 120 & & & & & \\
\hline
\end{tabular}


(Table 1) Contd.....

\begin{tabular}{|c|c|c|c|c|c|c|c|c|}
\hline Dep. Variable & Source & Type III SS & $d f$ & Mean Square & $F$ & $p$ & $b$ & $S E$ \\
\hline \multirow{6}{*}{ VEGD } & Corrected Model & 0.13 & 3 & 0.04 & 1.40 & $>0.2$ & & \\
\hline & Cephalothorax width & 0.01 & 1 & 0.01 & 0.33 & $>0.5$ & -0.06 & 0.11 \\
\hline & Abdomen area & 0.01 & 1 & 0.01 & 0.21 & $>0.6$ & -0.06 & 0.14 \\
\hline & Error & 3.57 & 117 & 0.03 & & & & \\
\hline & Total & 32.75 & 121 & & & & & \\
\hline & Corrected Total & 3.70 & 120 & & & & & \\
\hline \multirow{5}{*}{ WH } & Corrected Model & 0.69 & 3 & 0.23 & 7.18 & $<0.001$ & & \\
\hline & Sex & 0.07 & 1 & 0.07 & 2.22 & $>0.1$ & & \\
\hline & Error & 3.72 & 117 & 0.03 & & & & \\
\hline & Total & 184.51 & 121 & & & & & \\
\hline & Corrected Total & 4.41 & 120 & & & & & \\
\hline
\end{tabular}

Table 2. Results of GLMs with Sex as the Independent Factor, Size (Cephalothorax Width), Energy Reserves (Abdomen Area) and Total Capture Thread Length (TCTL) as Covariates, and Stabilimenta Area (STABA) and Length (STABL) as Dependent Variables. $b=$ the Slope from the GLM for Continuous Predictors

\begin{tabular}{|c|c|c|c|c|c|c|c|c|}
\hline Dep. Variable & Source & Type III SS & $d f$ & Mean Square & $F$ & $p$ & $b$ & $S E$ \\
\hline \multirow{8}{*}{ STABA } & Corrected Model & 1.40 & 4 & 0.35 & 26.62 & $<0.0001$ & & \\
\hline & Intercept & 0.16 & 1 & 0.16 & 12.24 & $<0.001$ & 0.80 & 0.22 \\
\hline & Cephalothorax width & 0.20 & 1 & 0.20 & 15.05 & $<0.0005$ & 0.32 & 0.08 \\
\hline & Abdomen area & 0.10 & 1 & 0.10 & 7.28 & $<0.01$ & 0.25 & 0.09 \\
\hline & TCTL & 0.04 & 1 & 0.04 & 2.70 & $>0.1$ & -0.08 & 0.05 \\
\hline & Error & 1.62 & 123 & 0.01 & & & & \\
\hline & Total & 109.34 & 128 & & & & & \\
\hline & Corrected Total & 3.03 & 127 & & & & & \\
\hline \multirow{6}{*}{ STABL } & Corrected Model & 4.23 & 4 & 1.06 & 74.50 & $<0.0001$ & & \\
\hline & TCTL & 0.26 & 1 & 0.26 & 18.61 & $<0.0001$ & 0.23 & 0.05 \\
\hline & Sex & 0.13 & 1 & 0.13 & 9.02 & $<0.005$ & & \\
\hline & Error & 1.75 & 123 & 0.01 & & & & \\
\hline & Total & 244.02 & 128 & & & & & \\
\hline & Corrected Total & 5.98 & 127 & & & & & \\
\hline
\end{tabular}

\section{Web Design and Placement}

All individuals built webs that contained a stabilimentum. A multivariate GLM with web height, stabilimentum length and area, mesh size, hub area, total capture thread length, and vegetation density as dependent variables was significant for sex and both covariates (sex: $\mathrm{F}_{7,111}=3.84, \mathrm{p}<$ 0.001 ; cephalothorax width: $\mathrm{F}_{7,111}=14.48, \mathrm{p}<0.0001$; abdomen area: $F_{7,111}=3.18, p<0.005$ ); hence univariate GLMs 

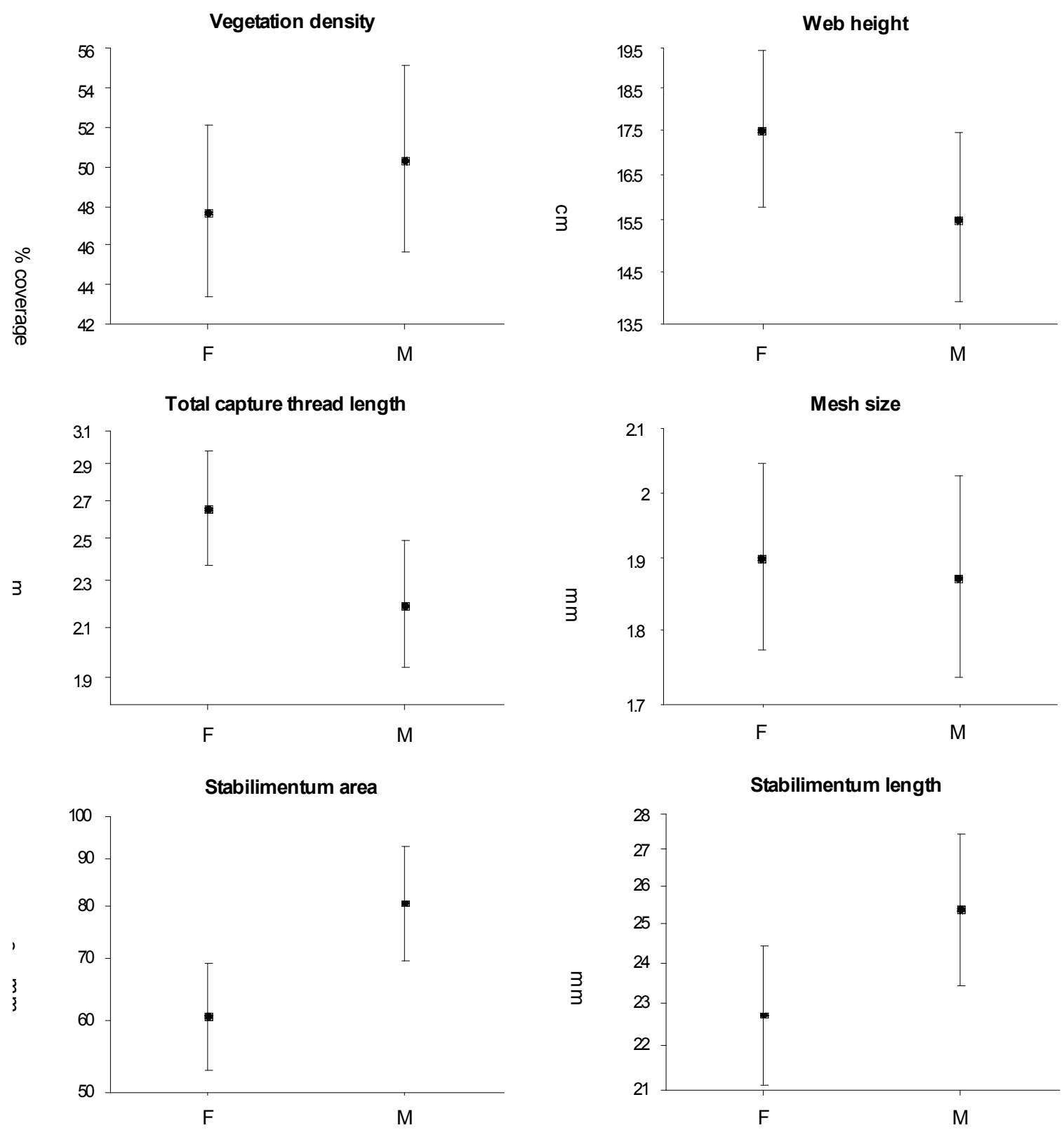

Hub area

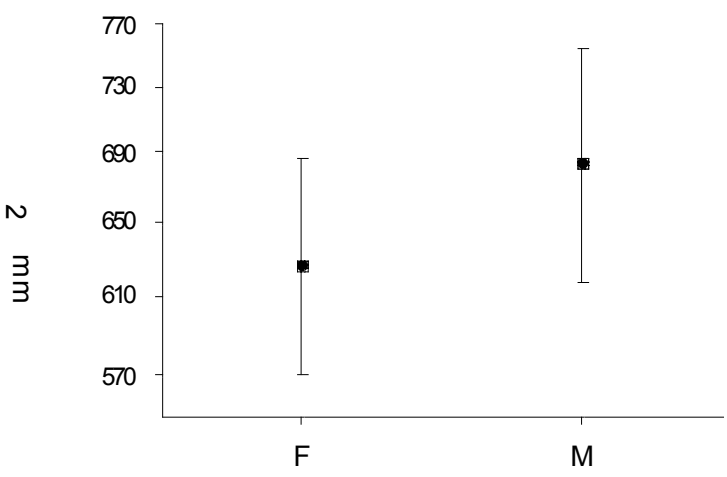

Fig. (2). Adjusted mean values within 95\% confidence limits (error bars) of web characteristics for females (F) and males (M). Shown are the back-transformed values (anti-log; areas also squared) on log scales except for vegetation density which did not have to transformed for analysis. For model details see text. 
were evaluated (Table 1). We had to exclude capture area from these analyses because including it lead to a serious violation of the assumption of homogeneity of variances and we could not find a transformation that would correct for this. However, capture area was highly correlated with total capture thread length (Pearson $\mathrm{r}=0.92, \mathrm{n}=129, \mathrm{p}<0.001$ ). Females built webs with a significantly longer capture thread, indicating that they built larger webs. Males built larger stabilimenta, the effect on stabilimentum length was marginally non-significant (Fig. 2). Furthermore, we performed a multivariate GLM with stabilimentum length and area as dependent variables and sex, size, condition, and total capture thread length as covariates to control additionally for web size (sex: $F_{2,122}=6.47, p<0.005$; cephalothorax width: $\mathrm{F}_{2,122}=22.08, \mathrm{p}<0.0001$; abdomen area: $\mathrm{F}_{2,122}=7.67, \mathrm{p}<$ 0.001 ; TCTL: $\mathrm{F}_{2,122}=10.54, \mathrm{p}<0.0001$ ), as well as consecutive univariate GLMs (Table 2). Males built larger and longer stabilimenta than females independent of web size (adjusted means $\pm 95 \% \mathrm{CI}$ : stabilimentum area, females $=$ $0.891 \pm 0.029$, males $=0.935 \pm 0.030 ;$ stabilimentum length, females $=1.332 \pm 0.030$, males $=1.400 \pm 0.032$ ). To analyse potential differences in stabilimentum shape construction we grouped stabilimenta into two categories, "containing a disc, with or without a linear component" and "linear, not containing a disc", because the disc constitutes a major component and because we found that only these two groups differed in size with discoid stabilimenta being larger on average (results not shown). A GLZ with stabilimentum shape as dichotomous response, sex as independent factor, and size and condition as covariates revealed no sex effect (females: stabilimenta including a disc $=61.4 \%$, males: $72.1 \%$, Wald $\chi^{2}=0.44, \mathrm{df}=1, \mathrm{p}>0.8$; cephalothorax width: $\mathrm{b} \pm \mathrm{SE}=6.32 \pm 1.62$, Wald $\chi^{2}=15.14, \mathrm{df}=1, \mathrm{p}<0.0001$ abdomen area: $\mathrm{b} \pm \mathrm{SE}=-3.41 \pm 1.81$, Wald $\chi^{2}=3.54, \mathrm{df}=1$, $\mathrm{p}=0.06)$.

Although we did not formally test hypotheses about size and condition effects, it is worth noting that larger spiders built webs that were higher up, had a longer capture thread length, a larger hub area, as well as a longer and larger stabilimentum (Tables 1 and 2). Spiders in better condition built webs that were lower down in the vegetation and that had a shorter capture thread, as well as a stabilimentum with a larger area (Table 1). When corrected for web size, spiders in better condition also built longer stabilimenta (Table 2). Further, larger individuals built more frequently a linear stabilimentum, whereas those in better condition for a given size tended to build discoid stabilimenta (see above).

Sticky traps placed near female webs $(n=16)$ caught significantly more prey (mean $\pm \mathrm{SE}=16.44 \pm 2.38)$ than traps set near male webs $(n=23$; mean $\pm \mathrm{SE}=7.26 \pm 0.68$; GLM with log-transformed prey count as the response and sex as fixed factor as well as cephalothorax width and abdomen area as co-variates: sex: $\mathrm{F}_{1,30}=9.66, \mathrm{p}<0.005$; cephalothorax width: $\mathrm{F}_{1,30}=0.34, \mathrm{p}>0.5$; abdomen area: $\mathrm{F}_{1,30}=$ 0.05, p > 0.8). Dipterans, Hemipterans, and Coleopterans were caught most frequently, with traps at female sites catching more (Fig. 3). Although overall not frequently caught, taxa including spider predators (Araneids and Hymenopterans) were also mostly associated with female sites. There was no difference in the size of available prey (trap means $\pm \mathrm{SE}$ : male sites $=2.94 \pm 0.158 \mathrm{~mm}$; female sites $=2.94 \pm 0.157 \mathrm{~mm}$; GLM with mean prey size as the response and sex as fixed factor as well as cephalothorax width and abdomen area as co-variates: sex: $\mathrm{F}_{1,30}=0.02, \mathrm{p}>$ 0.8 ; cephalothorax width: $\mathrm{F}_{1,30}=0.01, \mathrm{p}>0.9$; abdomen area: $\left.F_{1,30}=0.24, p>0.6\right)$. Spiders were found to build webs in white clover (Trifolium repens) more often than other plants $(72.5 \%)$, but no significant sex differences were found in the proportion of individuals that built webs in white clover $\left(\mathrm{M}=73.1 \% ; \mathrm{F}=71.9 \% ; \chi^{2}=0.54, \mathrm{p}>0.8\right)$. Our photographs of the sites did not allow for a more detailed analysis of the relative abundance of each plant species with confidence.

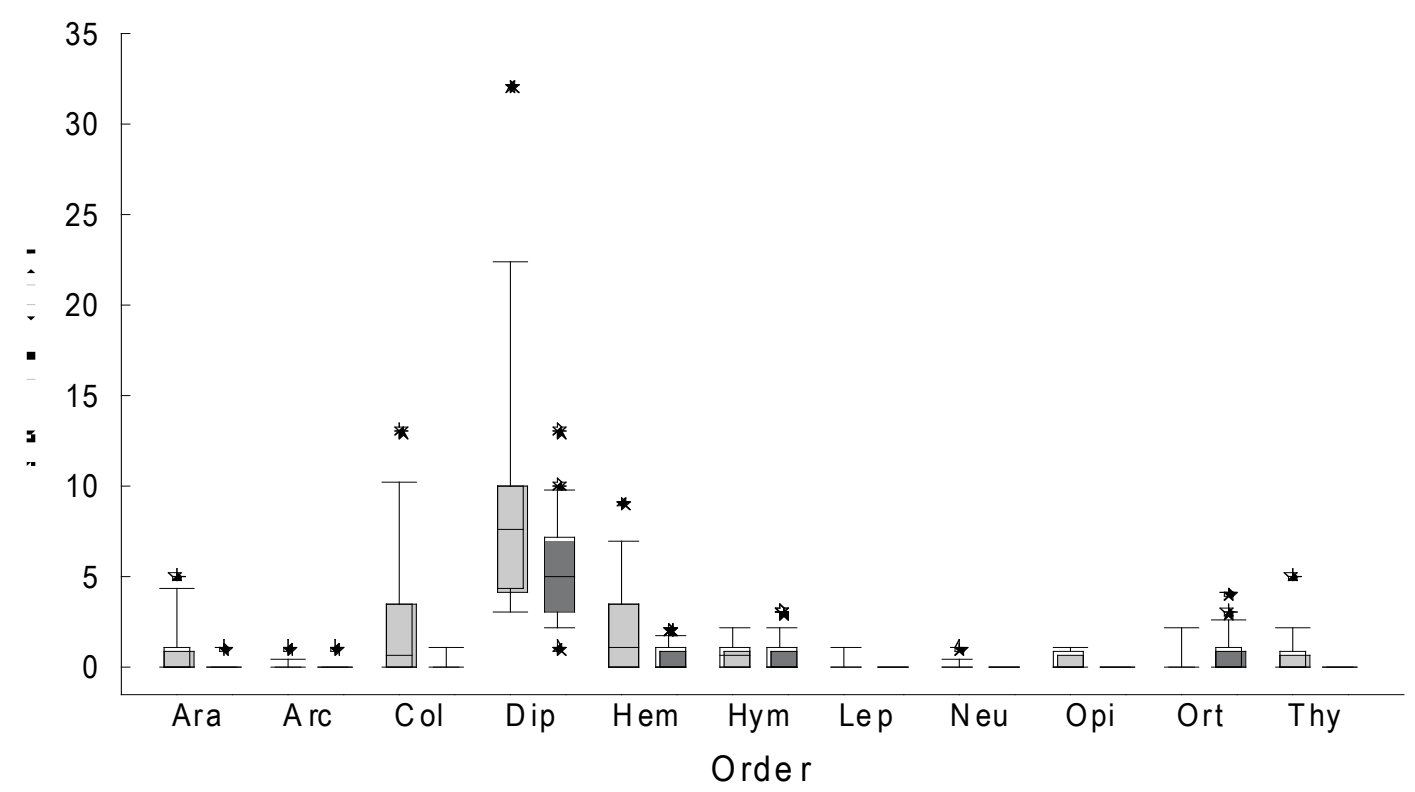

Fig. (3). Prey count per trap as a function of sex ( $F=$ female - open-, $M=$ male -solid-) categorized according to Order. Ara = Araneae; Arc $=$ Archaeognatha; $\mathrm{Col}=$ Coleoptera; Dip = Diptera; Hem = Hemiptera; Hym = Hymenoptera; Lep = Lepidoptera; Neu = Neuroptera; Opi = Opiliones; Ort $=$ Orthoptera; Thy $=$ Thysanoptera. Stars indicate extreme values (more than three box lengths outside the main body of data). 


\section{Web Site Tenacity and Distance Moved}

Forty-one percent (29/70) of spiders changed their web site during the four day experiment, and most only once ( $82 \%$ of spiders that moved). Hence we only analyzed whether spiders moved or not. Males and females did not differ significantly in web site tenacity $(38 \%$ females and $46 \%$ males changed web site, $\left.\chi^{2}=0.48, \mathrm{p}>0.4\right)$ or in distance traveled per web change (only movement events were considered, i.e. zeros excluded: sex effect in a GLM with initial size as covariate: $F_{1,25}=1.44, p>0.2$; mean distances $\pm \mathrm{SE}$ (untransformed): females $=36.83 \pm 7.42 \mathrm{~cm}$, males $=$ $25.65 \pm 4.67 \mathrm{~cm})$. There was no significant difference between the control and experimental spiders in the proportion of web site change (experimental spiders: $41 \%$, control: $30 \%$; Fisher's exact test: $\mathrm{p}>0.7)$.

\section{Growth Rates}

Because only 10 individuals (14\%) moulted during the four days each experimental trial was run, we evaluated growth during the experiment by comparing the increase in abdomen dimensions for male and female spiders that did not moult (moulting results in stored reserves being pumped from the abdomen into the frontal body parts). Therefore, for these spiders the only body part that could change as a function of food intake was the abdomen. The proportional increase in abdomen size (square-root transformed abdomen area) was larger for females than for males (mean \pm SE: females $=20.7 \pm 0.03 \%$, males $=6.5 \pm 0.03 \%$ ). We tested for sex-specific growth using a repeated measures GLM with abdomen area (before and after the trial) as the withinsubject factor (i.e. response), sex as the between-subject factor, and cephalothorax width as a covariate to control for structural size. The abdomen size $\mathrm{x}$ sex interaction was significant $\left(F_{1,55}=5.67, p<0.025\right.$, Fig. 4).

\section{DISCUSSION}

This study demonstrates that already early-instar male and female juveniles of a highly dimorphic species differ in growth rate and foraging behaviour under natural conditions. Female Argiope aurantia grew significantly larger during the four-day experimental period than males (Fig. 4). This is consistent with the finding that in spiders both sexual differences in development time and growth rate account for SSD (Blanckenhorn et al. 2007). Data from a laboratory population also suggest that in A. aurantia females grow faster and take longer to develop than males (Foellmer, Inkpen \& Bowden, unpublished manuscript). A comparison of wild-caught penultimate and adult males with females showed that females were larger, again pointing to the possibility that females grow faster (Howell and Ellender 1984). Further, our finding of sex-specific growth (i.e. weight gain) is unlikely to be the result of highly synchronized sexspecific growth trajectories (i.e. all males being caught close to moult and thus not feeding) because there is considerable variance in development under controlled laboratory conditions (Foellmer, Inkpen \& Bowden, unpublished manuscript) as well as in the field where maturation of both males and females is spread out over several weeks (Foellmer 2008, Foellmer and Fairbairn 2005). Unfortunately, we know generally very little about instar-specific growth rates in spiders in general, how these compare for females and males, and how they interact with environmental factors (see Fernandez-Montraveta and Moya-Laraño 2007, Uhl et al. 2004). No comprehensive quantitative genetic analysis of growth and development has yet been conducted for any highly dimorphic species, for which there is a clear need (Foellmer and Moya-Laraño 2007, Uhl et al. 2004).

Sex-specific growth rates that are manifest already early during the ontogeny in dimorphic species are probably a

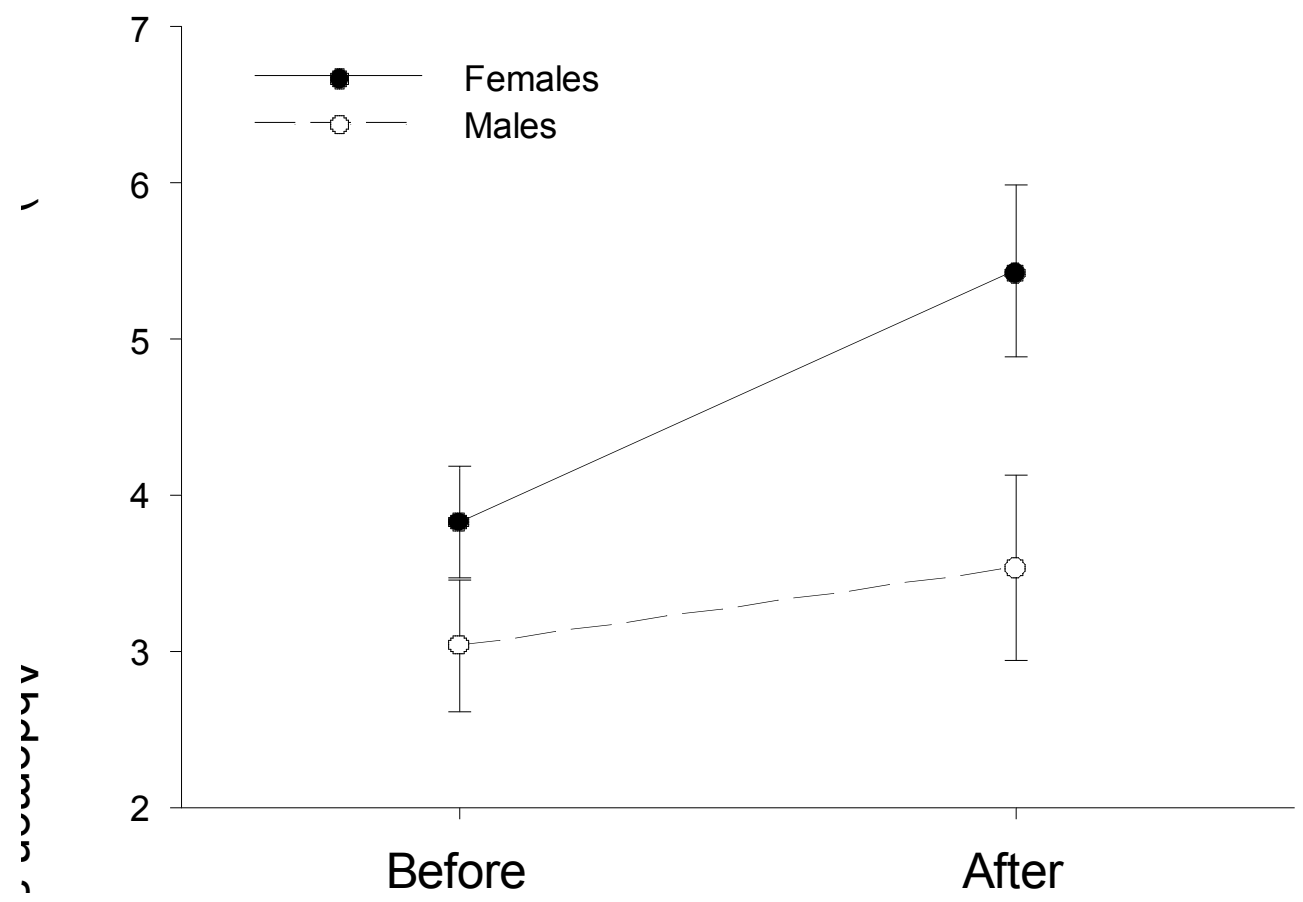

Fig. (4). Adjusted mean values within $95 \%$ confidence limits (error bars) of abdomen size for females and males before and after the fourday experimental trials. Shown are the back-transformed (squared) values. For model details see text. 
consequence of seasonal environments with distinct and brief mating periods (see Higgins 2000). In tropical regions without pronounced seasons mature females and males can be found year-round (Foelix 1996), removing the need to synchronize maturation at very different body sizes. For example, males of tropical Argiope spp. mature after half the number of moults compared to females, although data on sex-specific development times and growth rates are not available in this case (Robinson and Robinson 1978). Current evidence suggests that in most spider lineages with pronounced SSD, including the argiopoid clade within the Araneidae to which the genus Argiope belongs, females have grown larger over evolutionary time (Hormiga et al. 2000), probably because fecundity selection has been favouring large female size (Head 1995, Prenter et al. 1999). At the same time, selection must have been operating against an increase in male size, which would otherwise have been expected due to the generally high genetic correlations between male and female body size (Reeve and Fairbairn 2001). Hypotheses for the adaptive significance of relatively small male size have invoked selection operating on adult size per se or viability selection during the juvenile stages counteracting sexual selection for large size in adult males and high adult male mortality during mate search (De Mas et al. 2009, Foellmer and Moya-Laraño 2007). Viability selection during the juvenile stages should favour more careful foraging strategies that minimize exposure to predators or potentially dangerous prey at the cost of reduced growth (Mikolajewski et al. 2005, Verdolin 2006). In females, on the other hand, voracious foraging is predicted to be favoured to support the fast growth to large adult size (Blanckenhorn 2005). Hence, female foraging behaviours can be seen as a consequence of SSD, while male behaviours might be, at least to some extent, a cause of SSD (Blanckenhorn 2005). Below we discuss the sex-specific foraging behaviours of juvenile $A$. aurantia.

Females built larger webs than males, even when controlled for size and condition (Fig. 2, Table 1). This was accomplished by an increase in capture thread length while mesh size was the same in webs of males and females, thus reflecting a greater silk investment by females. Males on the other hand constructed larger stabilimenta, and this was also true when web size was controlled for in addition to size and condition (Table 2) (stabilimenta constitute a relatively minor silk investment though, compared to the actual capture webs - Blackledge 1998). This latter result is contrary to our predictions. The larger webs built by females likely increase their foraging success by intercepting a greater number of airborne prey (Blackledge and Eliason 2007, Bruce et al. 2001). A second means of increasing foraging success, at least in adults, is decreasing mesh size, because dense webs are better at retaining large and powerful prey long enough for the spider to rush to the prey and wrap it (Blackledge and Eliason 2007, Blackledge and Zevenbergen 2006). The fact that females increase web size without increasing mesh size hints at the importance of maintaining a given mesh size. It is possible that further decreasing mesh size does not yield enough benefits in terms of capturing prey that is available to juveniles, relative to the cost of placing down more silk.

The function of stabilimenta is controversial and shapes and sizes vary greatly in spiders both at the interspecific and intraspecific level (Blackledge 1999, Bruce 2006, Bruce and
Herberstein 2005, Herberstein et al. 2000, Seah and Li 2001). In short, the two hypotheses that have received most support are the prey attraction and predator avoidance hypotheses. The first hypothesis states that stabilimenta attract prey (they reflect in the UV spectrum visible to insects), while the latter proposes that the stabilimenta conceal the spider or distract predators such as wasps (for the most recent review see Bruce 2006). The function of stabilimenta in juvenile spiders has so far been tested in only one species, the congener $A$. versicolor, supporting the preyattraction hypothesis ( $\mathrm{Li}$ and Lee 2004, Li et al. 2004). Based on this finding we predicted that females would build larger stabilimenta, the opposite of which we found. Compared to females, males should pursue a careful foraging strategy that minimizes mortality risk (see above). Based on this argument, it is possible that stabilimenta function to protect against predators in juvenile $A$. aurantia, since males invest more in them. This is further supported by the fact that spiders in better condition build larger stabilimenta. If stabilimenta served to attract prey, one would have expected individuals in worse condition (i.e. hungry ones) to construct larger stabilimenta (Blackledge 1998). However, stabilimentum construction may simply be constrained by the condition of individuals, i.e. by available silk reserves (Tso 2004). Interestingly, the sexes did not differ significantly regarding the shape of the stabilimenta they built. Larger spiders built linear ones (without any disc) more frequently, likely reflecting the shift from the discoid shape typical of young juveniles to linear typical of later juveniles and adults (Bruce and Herberstein 2005). The significance of the ontogenetic shift in stabilimentum shape in spiders is still not understood and warrants further study. Finally, we have to stress that we did not specifically test for the function of stabilimenta. Such a study, involving several ontogenetic stages, should add important insight into the possible context-dependent function and evolutionary lability of stabilimenta in spiders (Bruce 2006).

The sites that males and females chose to build their webs in differed clearly in terms of prey availability; sites occupied by females exhibited a higher prey abundance than sites occupied by males. However, this difference in prey availability did not correlate with any other variable that we measured to evaluate web sites: there was no difference in vegetation density and both males and females built webs predominantly in white clover (Trifolium repens). Furthermore, both sexes built their webs at the same height. Previously it had been suggested that individuals building webs higher up in less dense vegetation could intercept larger flying prey (Brown 1981; but see Enders 1976); however, prey capture rate has also been shown to be unaffected by web height and that spiders do not change web height according to prey abundance (Herberstein 1997, Herberstein 2000, Prokop and Gryglakova 2005). It is likely that either small increases in web height (only $10 \mathrm{~cm}$ or so) at the juvenile stage do not affect the type of prey caught, or web height is the result of available abiotic factors and seasonal growth only, and has little effect on prey capture (Herberstein 1997, McReynolds 2000). A recent study found that plant species composition best predicts the nature of arthropod assemblages, and that vegetation structure is much less important (Schaffers et al. 2008). It is possible that our limited ability to resolve plant species composition with 
confidence has diminished our power to detect any influence of plant composition. However, it remains to be tested whether and to what extent differences in plant species assemblages affect insects and spiders at scales as small as those relevant here (i.e. within $0.5 \mathrm{~m}$ ). To this end, the reason why female sites had higher insect numbers remains open for investigation.

We did not find any sex differences in website tenacity or distance travelled during website changes. We predicted that females would change web-sites more frequently than males in search of microhabitats with greater food availability (Werner and Anholt 1993), indicating a higher low-food threshold to decrease the variance in foraging success (but see Edwards et al. 2009). Our result is puzzling because females were found in areas with greater prey availability and grew faster. It is possible that movement is random and does not reflect prey availability (e.g. Chmiel et al. 2000, Nakata and Ushimaru 1999) as much as other factors such as web destruction, conspecific interactions, or environmental changes (e.g. Chmiel et al. 2000, Smallwood 1993). Alternatively, following individuals for four days may not have been enough to detect sex-specific differences in web site tenacity, but as stated above, this is unlikely because the previously reported average web site tenacity for juveniles was less than four days (Enders 1976).

In conclusion, we have shown that male and female juvenile A. aurantia differ in growth rate and foraging behaviour under natural conditions. Females grow faster and build larger webs at sites with greater prey density, whereas males construct larger stabilimenta in the centers of their webs. The significance of this last result requires further study because the role of stabilimenta is still controversial and necessitates a case-by-case analysis. Two more important avenues for future investigation are to what extent the sexes trade off differentially foraging behaviour with mortality risk and in what ways males and females differ in foraging behaviour on the web (vs. web building behaviour, which we evaluated here). The foraging - mortality trade-off is predicted because females probably expose themselves to predators or potentially dangerous prey to a greater extent than males (Mikolajewski et al. 2005, Verdolin 2006). Males on the other hand probably suffer from a high mortality as adults during mate search (Andrade 2003, De Mas et al. 2009, Kasumovic et al. 2007, but see Fromhage et al. 2007), and hence are expected to be under strong viability selection to survive to adulthood (Vollrath and Parker 1992). Indeed, the operational and effective sex ratios are male-biased in $A$. aurantia (Foellmer 2008), and may be so in other similar systems as well (Fromhage et al. 2007, Miller 2007). Thus, the analysis of the foraging - mortality trade-off is crucial for understanding the evolution of extreme SSD.

\section{ACKNOWLEDGEMENTS}

We would like to acknowledge Christopher Ayer and Jonathan Dykeman for their help with the field work. Jeremy Lundholm kindly helped with the identification of plants. Jordi Moya-Laraño and an anonymous reviewer made valuable suggestions on a previous draft that improved the paper substantially. The study was supported by an Undergraduate Study Research Award from the Natural
Sciences and Engineering Research Council of Canada (NSERC) to A.I. and by a NSERC Discovery Grant (RGPIN/329184-2006) to M.W.F.

\section{REFERENCES}

Andrade, MCB (2003) Risky mate search and male self-sacrifice in redback spiders. Behavioral Ecology, 14, 531-538.

Blackledge, TA (1998) Stabilimentum variation and foraging success in Argiope aurantia and Argiope trifasciata (Araneae: Araneidae). Journal of Zoology, 246, 21-27.

Blackledge, TA (1999) Do stabilimenta in orb webs attract prey or defend spiders? Behavioral Ecology, 10, 372-376.

Blackledge, TA \& Eliason, CM (2007) Functionally independent components of prey capture are architecturally constrained in spider orb webs. Biology Letters, 3, 456-458.

Blackledge, TA \& Zevenbergen, JM (2006) Mesh width influences prey retention in spider orb webs. Ethology, 112, 1194-1201.

Blanckenhorn, W, Dixon, AFG, Fairbairn, DJ, Foellmer, MW, Gibert, P, van der Linde, K, Meier, R, Nylin, S, Pitnick, S, Schoff, C, Signorelli, M, Teder, T \& Wiklund, C (2007) Proximate causes of Rensch's rule: Does sexual size dimorphism in arthropods result from sex differences in development time? American Naturalist, $169,245-257$.

Blanckenhorn, WU (2005) Behavioral causes and consequences of sexual size dimorphism. Ethology, 111, 977-1016.

Brown, KM (1981) Foraging ecology and niche partitioning in orb-weaving spiders. Oecologia, 50, 380-385.

Bruce, MJ (2006) Silk decorations: controversy and consensus. Journal of Zoology, 269, 89-97.

Bruce, MJ \& Herberstein, ME (2005) Web decoration polymorphism in Argiope Audouin, 1826 (Araneidae) spiders: ontogenetic and interspecific variation. Journal of Natural History, 39, 3833-3845.

Bruce, MJ, Herberstein, ME \& Elgar, MA (2001) Signalling conflict between prey and predator attraction. Journal of Evolutionary Biology, 14, 786-794.

Chmiel, K, Herberstein, ME \& Elgar, MA (2000) Web damage and feeding experience influence web site tenacity in the orb-web spider Argiope keyserlingi Karsch. Animal Behaviour, 60, 821-826.

De Mas, E, Ribera, C \& Moya-Laraño, J (2009) Resurrecting the differential mortality model of sexual size dimorphism. Journal of Evolutionary Biology 22, 1739-1749.

Edwards, W, Whytlaw, PA, Congdon, BC \& Gaskett, C (2009) Is optimal foraging a realistic expectation in orb-web spiders? Ecological Entomology, 34, 527-534.

Enders, F (1976) Effects of prey capture, web design and habitat physiognomy on web-site tenacity of Argiope spiders (Araneidae). Journal of Arachnology, 3, 75-82.

Esperk, T, Tammaru, T, Nylin, S \& Teder, T (2007) Achieving high sexual size dimorphism in insects: Females add instars. Ecological Entomology, 32, 243-256.

Fairbairn, DJ (1997) Allometry for sexual size dimorphism: Pattern and process in the coevolution of body size in males and females. Annual Review of Ecology and Systematics, 28, 659-687.

Fairbairn, DJ, Blanckenhorn, WU \& Székely, T (2007) Sex, Size and Gender Roles: Evolutionary Studies of Sexual Size Dimorphism, Oxford, Oxford University Press.

Fernandez-Montraveta, C \& Moya-Laraño, J (2007) Sex-specific plasticity of growth and maturation size in a spider: implications for sexual size dimorphism. Journal of Evolutionary Biology, 20, 1689-1699.

Foelix, RF (1996) Biology of Spiders, New York, Oxford University Press.

Foellmer, MW (2008) Broken genitals function as mating plugs and affect sex ratios in the orb-web spider Argiope aurantia. Evolutionary Ecology Research, 10, 449-462.

Foellmer, MW \& Fairbairn, DJ (2005) Selection on male size, leg length and condition during mate search in a sexually highly dimorphic orb-weaving spider. Oecologia, 142, 653-662.

Foellmer, MW \& Moya-Laraño, J (2007) Sexual size dimorphism in spiders: patterns and processes. In Fairbairn, DJ, Blanckenhorn, WU \& Székely, T. (Eds.) Sex, Size and Gender Roles: Evolutionary Studies of Sexual Size Dimorphism. Oxford, Oxford University Press.

Fromhage, L, Jacobs, K \& Schneider, JM (2007) Monogynous Mating Behaviour and its Ecological Basis in the Golden Orb Spider Nephila fenestrata. Ethology, 113, 813-820. 
Ghiselin, MT (1974) The Economy of nature and the Evolution of Sex, Berkeley, University of California Press.

Head, G (1995) Selection on fecundity and variation in the degree of sexual size dimorphism among spider species (class Araneae). Evolution, 49, 776-781.

Heiling, AM, Herberstein, ME \& Spitzer, G (1998) Calculation of capture thread length in orb webs: Evaluation of new formulae. Annals of the Entomological Society of America, 91, 135-138.

Herberstein, ME (1997) The effect of habitat structure on web height preference in three sympatric web-building spiders (Araneae, Linyphiidae). Journal of Arachnology, 25, 93-96.

Herberstein, ME (2000) Foraging behaviour in orb-web spiders (Araneidae): do web decorations increase prey capture success in Argiope keyserlingi Karsch, 1878? Australian Journal of Zoology, 48, 217 223.

Herberstein, ME, Craig, CL, Coddington, JA \& Elgar, MA (2000) The functional significance of silk decorations of orb-web spiders: a critical review of the empirical evidence. Biological Reviews, 75, 649-669.

Herberstein, ME \& Tso, IM (2000) Evaluation of formulae to estimate the capture area and mesh height of orb webs (Araneoidea, Araneae). Journal of Arachnology, 28, 180-184.

Higgins, L (2000) The interaction of season length and development time alters size at maturity. Oecologia, 51-59.

Hormiga, G, Scharff, N \& Coddington, JA (2000) The phylogenetic basis of sexual size dimorphism in orb-weaving spiders (Araneae, Orbiculariae). Systematic Biology, 49, 435-462.

Howell, FG \& Ellender, RD (1984) Observations on growth and diet of Argiope aurantia Lucas (Araneidae) in a successional habitat. Journal of Arachnology, 12, 29-36.

Kasumovic, MM, Bruce, MJ, Herberstein, ME \& Andrade, MCB (2007) Risky mate search and mate preference in the golden orb-web spider (Nephila plumipes). Behavioral Ecology, 18, 189-195.

Kleinbaum, DG, Kupper, LL, Muller, KE \& Nizam, A (1998) Applied Regression Analysis and Other Multivariable Methods, Pacific Grove, Duxbury Press.

Levi, HW (1968) The spider genera Gea and Argiope in America (Araneae: Araneidae). Bulletin of the Museum of Comparative Zoology, 136, 319-352.

Li, DQ \& Lee, WS (2004) Predator-induced plasticity in web-building behaviour. Animal Behaviour, 67, 309-318.

Li, DQ, Lim, MLM, Seah, WK \& Tay, SL (2004) Prey attraction as a possible function of discoid stabilimenta of juvenile orb-spinning spiders. Animal Behaviour, 68, 629-635.

Mahmoudi, N, Modanu, M, Brandt, Y \& Andrade, MCB (2008) Subtle pedipalp dimorphism: a reliable method for sexing juvenile spiders. Journal of Arachnology, 36, 513-517.

McReynolds, CN (2000) The impact of habitat features on web features and prey capture of Argiope aurantia (Araneae, Araneidae). Journal of Arachnology, 28, 169-179.
Mikolajewski, DJ, Brodin, T, Johansson, F \& Joop, G (2005) Phenotypic plasticity in gender specific life-history: effects of food availability and predation. Oikos, 110, 91-100.

Mikolajewski, DJ, Joop, G \& Wohlfahrt, B (2007) Coping with predators and food limitation: testing life history theory for sex-specific larval development. Oikos, 116, 642-649.

Miller, JA (2007) Repeated evolution of male sacrifice behavior in spiders correlated with genital mutilation. Evolution, 61, 1301-1315.

Nakata, K \& Ushimaru, A (1999) Feeding experience affects web relocation and investment in web threads in an orb-web spider. Cyclosa argenteoalba. Animal Behaviour, 57, 1251-1255.

Prenter, J, Elwood, RW \& Montgomery, WI (1999) Sexual size dimorphism and reproductive investment by female spiders: a comparative analysis. Evolution, 53, 1987-1994.

Prokop, P \& Gryglakova, D (2005) Factors affecting the foraging success of the wasp-like spider Argiope bruennichi (Araneae): Role of web design. Biologia, 60, 165-169.

Reeve, JP \& Fairbairn, DJ (2001) Predicting the evolution of sexual size dimorphism. Journal of Evolutionary Biology, 14, 244-254.

Robinson, B \& Robinson, MH (1978) Developmental studies of Argiope argentata (Fabricius) and Argiope aemula (Walkenaer). Symposia of the Zoological Society, London, 42, 31-40.

Sandoval, CP (1994) Plasticity in web design in the spider Parawixia bistriata - a response to variable prey type. Functional Ecology, 8, 701-707.

Schaffers, AP, Raemakers, IP, Sykora, KV \& Ter Braak, CJF (2008) Arthropod assemblages are best predicted by plant species composition. Ecology, 89, 782-794.

Seah, WK \& Li, DQ (2001) Stabilimenta attract unwelcome predators to orb-webs. Proceedings of the Royal Society of London Series BBiological Sciences, 268, 1553-1558.

Smallwood, PD (1993) Web-site tenure in the long-jawed spider - is it risksensitive foraging, or conspecific interactions. Ecology, 74, 18261835 .

Tso, IM (2004) The effect of food and silk reserve manipulation on decoration-building of Argiope aetheroides. Behaviour, 141, 603616.

Uetz, GW (1992) Foraging strategies of spiders. Trends in Ecology and Evolution, 7, 155-159.

Uhl, G, Schmitt, S, Schafer, MA \& Blanckenhorn, W (2004) Food and sexspecific growth strategies in a spider. Evolutionary Ecology Research, 6, 523-540.

Verdolin, JL (2006) Meta-analysis of foraging and predation risk trade-offs in terrestrial systems. Behavioral Ecology and Sociobiology, 60, 457-464.

Vollrath, F (1998) Dwarf males. Trends in Ecology and Evolution, 13, 159163.

Vollrath, F \& Parker, GA (1992) Sexual dimorphism and distorted sex ratios in spiders. Nature, 360, 156-159.

Werner, EE \& Anholt, BR (1993) Ecological consequences of the trade-off between growth and mortality-rates mediated by foraging activity. American Naturalist, 142, 242-272.

Received: March 14, 2010

Revised: May 23, 2010

Accepted: May 31, 2010

(C) Inkpen and Foellmer; Licensee Bentham Open.

This is an open access article licensed under the terms of the Creative Commons Attribution Non-Commercial License (http://creativecommons.org/licenses/by$\mathrm{nc} / 3.0 /$ ), which permits unrestricted, non-commercial use, distribution \& reproduction in any medium, provided the work is properly cited. 